\title{
The Application of Evaluation Sheet for Patients Needed Clean Intermittent Catheterization
}

\author{
Cuiqing Liu, Jing liu, Yanfei Li, Weiju Chen* \\ The First Affiliated Hospital of Jinan University, Guangzhou, China
}

Email address:

weiju_chen@sina.com (Weiju Chen)

${ }^{*}$ Corresponding author

To cite this article:

Cuiqing Liu, Jing liu, Yanfei Li, Weiju Chen. The Application of Evaluation Sheet for Patients Needed Clean Intermittent Catheterization. Journal of Family Medicine and Health Care. Vol. 2, No. 2, 2016, pp. 10-12. doi: 10.11648/j.jfmhc.20160202.11

Received: April 20, 2016; Accepted: June 22, 2016; Published: August 1, 2016

\begin{abstract}
To evaluate the mastery level of clean catheterization-related knowledge and operational procedures for patients/caregivers that needed clean intermittent catheterization of spinal cord injury, evaluation sheet was applied to sixty cases of spinal cord injury patients or their caregivers to evaluate their mastery level of clean catheterization-related knowledge and operational procedures. Then according to the results, individually targeted guidance was given until all the seven items of the sheet were reached 'yes'. Sixty patients can all master clean intermittent catheterization, 43 patients recovered reflex bladder, with 29 cases of residual urine volume (PVR) less than $80 \mathrm{ml}, 6$ cases of PVR ranging from 80-200 ml, and 8 cases of PVR ranging from 200-250 ml; 17 patients didn't recover reflex bladder. The evaluation sheet for clean intermittent catheterization can largely standardize the education content and operating procedures from clinical nursing, help nurses to evaluate the mastery levels of patients/caregivers with clean intermittent catheterization of spinal cord injury.
\end{abstract}

Keywords: Spinal Cord Injury, Clean Intermittent Catheterization, Evaluate Sheet, Nursing

\section{Introduction}

Clean intermittent catheterization (CIC) is a method for intermittent self-catheterization according to the bladder filling situation, with special cleaning catheter, with an interval of 3-4 h [1]. Clean intermittent catheterization is safe and reliable, is also a simple, easy and economical urinary tract management method, which has been widely used for the functional recovery training of spinal cord injury patients $[2$, 3]. CIC is now considered the standard of care for most neurologic patients with lower urinary tract disorders [4]. Comparing to other methods, such as indwelling catheterization, supra-pubic tube insertion, the Crede manoeuver or reflex micturition, CIC has improved quality of life and decreased mid- and long-term urinary tract complications [5, 6]. CIC is the mainstay of urologic management, which has been suggested that proactive implementation of CIC can decrease the risk of renal deterioration $[7,8]$. However, in neurologic patients, the bacteriuria rate is high and repeated urethral manipulations is associated with urethral trauma and strictures [9], if the skill is not properly mastered. Bladder function recovery of spinal cord injury needs the participation of patients itself or their caregiver. Learned from the catheterization education and internship program of department of orthopedics of Hong Kong Tuen Mun Hospital, we created the evaluation sheet and applied to spinal cord injury patients from May 2008 to Jun 2013. The use of sheet resulted excellent outcome when evaluating the catheterization technique, Troubleshooting, compliance behavior of patient/caregivers.

\section{Materials and Methods}

\subsection{Patients Selection}

From May 2008 to Jun 2013, 60 spinal cord injury patients that needed clean intermittent catheterization from 4 independent hospitals in Guangdong province were included. 37 cases were male and 23 cases were female, with average age 35 (ranging from 16 to 61). The average number of days in hospital was 35 . The education status and other information were not considered in the current study. 


\subsection{The Design of Evaluation Sheet}

Learned from the catheterization education and internship program of department of orthopedics of Hong Kong Tuen Mun Hospital, we designed the sheet with two main content covering the subjective and objective sections (Table 1). Subjective section is designed for the self-evaluation of patients/caregivers, containing 7 items, to select 'yes' or 'no' according their situation; Objective section containing 6 items, is designed for nurses to check the level of achievement of patients, to choose 'excellent', 'good', 'passed', 'unsatisfied' and 'bad'.

\subsection{Health Education}

First provide patients/caregivers an illustrated guidebook of clean intermittent catheterization, a water drinking plan and objects for operation, to give the patients/caregivers an initial knowledge of CIC; then our nurses will educate the patients. The education content was related to subjective section of the designed evaluation sheet, explaining combined with the guidance and answering all the questions from patients/caregivers. Finally, our nurses will give 10 times of operation demonstration of CIC for patients/caregivers.

Table 1. The evaluation sheet for clean intermittent catheterization (CIC).

\begin{tabular}{|c|c|c|c|}
\hline \multicolumn{2}{|l|}{ Items } & \multicolumn{2}{|l|}{ Results } \\
\hline \multicolumn{4}{|c|}{ Section 1 (filled by patient/caregiver) } \\
\hline \multicolumn{2}{|l|}{ 1. Know exactly of the aim } & Yes $\square$ & No $\square$ \\
\hline \multicolumn{2}{|c|}{ 2. Know exactly of the procedure of CIC? } & Yes $\square$ & No $\square$ \\
\hline \multicolumn{2}{|c|}{ 3. Know exactly of the nursing of CIC? } & Yes $\square$ & No $\square$ \\
\hline \multicolumn{2}{|c|}{$\begin{array}{l}\text { 4. Know exactly of the complications of } \\
\text { CIC? }\end{array}$} & Yes $\square$ & No $\square$ \\
\hline \multicolumn{2}{|c|}{$\begin{array}{l}\text { 5. Know how to handle the complications of } \\
\text { CIC? }\end{array}$} & Yes $\square$ & No $\square$ \\
\hline \multicolumn{2}{|c|}{ 6. Satisfied with the explanations of CIC? } & Yes $\square$ & No $\square$ \\
\hline \multicolumn{2}{|c|}{ 7. Confident to perform CIC? } & Yes $\square$ & No $\square$ \\
\hline \multicolumn{4}{|l|}{ Section 2 (filled by nurse) } \\
\hline \multicolumn{4}{|l|}{ 1. Environmental preparation } \\
\hline \multicolumn{4}{|l|}{ 2. Washing program } \\
\hline $\begin{array}{l}\text { Excellent } \square \quad \text { Good } \square \\
\text { 3. Object preparation }\end{array}$ & Passed $\square$ & Satisfied $\square$ & Bad $\square$ \\
\hline $\begin{array}{l}\text { Excellent } \square \quad \text { Good } \square \\
\text { 4. Body position preparati }\end{array}$ & Passed $\square$ & Satisfied $\square$ & $\operatorname{Bad} \square$ \\
\hline $\begin{array}{l}\text { Excellent } \square \quad \text { Good } \square \\
\text { 5. Executing procedure }\end{array}$ & Passed $\square$ & Satisfied $\square$ & Bad $\square$ \\
\hline Excellent $\square$ & Passed $\square$ & Satisfied $\square$ & Bad $\square$ \\
\hline
\end{tabular}

\subsection{Evaluation}

Subjective evaluation: at 2 days after education, patients/caregivers were taken subjective evaluation and nurses will take one by one item further education, until all the 7 items were reached 'yes'. Objective evaluation: after all the 7 times were kicked 'yes' by patients/caregivers, nurses will evaluate the practical operation by patients/caregivers' independently. According to the 'unsatisfied' or 'bad' items, nurses will take further operation demonstrations. Patients/caregivers can repeated practice until all the objective items were reached 'passed' or higher level. Then patients or caregivers can take CIC by themselves.

\section{Results}

All the Sixty patients can master clean intermittent catheterization, among which 43 patients recovered reflex bladder. 29 cases of residual urine volume (PVR) less than 80 $\mathrm{ml}$ stopped CIC; 8 cases of PVR ranging from $200-250 \mathrm{ml}, 2$ daily catheterizations were taken early in the morning and bedtime in the night; 6 cases of PVR ranging from 80-200 ml, 1 daily catheterization was taken bedtime in the night; 17 patients didn't recover reflex bladder, needing 4-6 times of catheterizations each day. Based on a 6 month follow-up, patients than needed CIC can insist self-catheterization and took examinations back to hospital; patients that were still hospitalized can positively give their feedbacks when encountering problems and receive timely response from doctors.

\section{Discussion}

CIC is an economical, simple and feasible therapeutic approach for the neurogenic bladder dysfunction [10, 11]. Once the bladder dysfunction occurs within spinal cord injury patients, it will severely affect the quality of their daily life or even lead to urinary tract infection [12, 13]. Neurogenic bladder treatment guidelines all recommend CIC for the bladder function training for spinal cord injury patients, to recovery the independent urination. To recover the voiding dysfunction of spinal cord injury patients becomes a spotlight search area, over $30 \%$ of these patients agree that urination and bowel dysfunction have the biggest impact on quality of life [14-16]. CIC is widely accepted as the most scientific management methods of urine tract $[17,18]$.

However, CIC is not always accepted by the patients. Urethral pain, urinary tract infection, fear of catheterization, the impossibility of achieving the correct, maneuver complexity, secure gesture, and failure to learn adequate technique are the main reasons from patients [19]. Also, physical limitations are also important obstacles to learn CIC. Thus we developed the evaluation sheet, containing some common question concerned, to evaluate the mastery level of patients. Many reasons can lead to the impossibility to learn or practice CIC, including paralysis, sensory or coordination alteration, or spasticity interfering with catheterization. Also, visual problems will lead to difficulty to reach the urinary meatus and physical dysfunction, cognitive impairment and psychological status will lead to the limited practice of CIC. Patient unwillingness, aversion and technique nonacceptance should be evaluated. According to the literature, 1/3 of the patients experience CIC as aversive with significantly higher distress scores on the general health questionnaire [20]. Usually, younger patients and females are often reporting aversion and distress. General determinants of therapeutic adherence are related to knowledge, misconceptions, complexity, fear, motivation and shame [21].

Our designed CIC evaluation sheet clearly provide a health education guideline for patients. The content and methods can all be revealed within the sheet. Key performance indicator are 
all listed to evaluate the effect of educations from nurses, which plays a supervisory role. The sheet ensures the educations from nurses must be done practically. Also the sheet evaluates the theoretical knowledge and practical skills of patients/caregivers, enrolling the evaluation, education, practice and improvement, until all the aspects were mastered. This largely reduced errors from efferent qualification of nurses and poor ability of patients and standardized the procedure and content.

The functional recovery period of spinal cord injury patients cannot be relied on the long-term or even lifelong care by nurses, but can be done by themselves or their caregivers who know how to perform CIC. Thus the education of CIC for patients/caregivers are tangibly needed. Our designed evaluation sheet for CIC training can fully evaluate the mastery levels of the knowledge and procedure of CIC, giving the patients/caregivers ability to perform CIC correctly and to handle problems encountered at home.

\section{Acknowledgement}

The authors declare no conflict of interest. This work was supported by Medical Scientific Research Foundation of Guangdong Province, China (No. A2012344).

\section{References}

[1] Newman, D. K. and M. M. Willson, Review of intermittent catheterization and current best practices. Urol Nurs, 2011. 31 (1): p. 12-28, 48; quiz 29.

[2] Spinu, A., et al., Intermittent catheterization in the management of post spinal cord injury (SCI) neurogenic bladder using new hydrophilic, with lubrication in close circuit devices--our own preliminary results. J Med Life, 2012.5 (1): p. 21-8.

[3] Sorokin, I. and E. De, Options for independent bladder management in patients with spinal cord injury and hand function prohibiting intermittent catheterization. Neurourol Urodyn, 2015. 34 (2): p. 167-76.

[4] Groen, J., et al., Summary of European Association of Urology (EAU) Guidelines on Neuro-Urology. Eur Urol, 2016. 69 (2): p. 324-33.

[5] Maynard, F. M. and A. C. Diokno, Clean intermittent catheterization for spinal cord injury patients. J Urol, 1982. 128 (3): p. 477-80.

[6] Sutton, G., S. Shah, and V. Hill, Clean intermittent self-catheterisation for quadriplegic patients--a five year follow-up. Paraplegia, 1991. 29 (8): p. 542-9.

[7] Edelstein, R. A., et al., The long-term urological response of neonates with myelodysplasia treated proactively with intermittent catheterization and anticholinergic therapy. J Urol, 1995. 154 (4): p. 1500-4.
[8] Kaye, I. Y., M. Payan, and V. M. Vemulakonda, Association between clean intermittent catheterization and urinary tract infection in infants and toddlers with spina bifida. J Pediatr Urol, 2016.

[9] Webb, R. J., A. L. Lawson, and D. E. Neal, Clean intermittent self-catheterisation in 172 adults. Br J Urol, 1990. 65 (1): p. 20-3.

[10] Lemke, J. R., K. Kasprowicz, and P. S. Worral, Intermittent catheterization for patients with a neurogenic bladder: sterile versus clean: using evidence-based practice at the staff nurse level. J Nurs Care Qual, 2005. 20 (4): p. 302-6.

[11] Obara, K., et al., [The consequence after introduction of clean intermittent catheterization (CIC) in children with neurogenic bladder dysfunction secondary to spina bifida--the comparison of patients with and without upper urinary tract dilation at the time CIC was introduced]. Nihon Hinyokika Gakkai Zasshi, 2003. 94 (7): p. 664-70.

[12] Vigil, H. R. and D. R. Hickling, Urinary tract infection in the neurogenic bladder. Transl Androl Urol, 2016. 5 (1): p. 72-87.

[13] McKibben, M. J., et al., Urinary Tract Infection and Neurogenic Bladder. Urol Clin North Am, 2015. 42 (4): p. 527-36.

[14] Ozisler, Z., et al., Outcomes of bowel program in spinal cord injury patients with neurogenic bowel dysfunction. Neural Regen Res, 2015. 10 (7): p. 1153-8.

[15] Pan, Y., et al., Bowel dysfunction in spinal cord injury: current perspectives. Cell Biochem Biophys, 2014. 69 (3): p. 385-8.

[16] Raza, S. J., et al., Lack of improvement after audit assessing the management of voiding dysfunction in patients with spinal cord injury: necessity for institutional guidelines. Int J Surg, 2011. 9 (4): p. 302-5.

[17] Oh, S. J., et al., Health-related quality of life of patients using clean intermittent catheterization for neurogenic bladder secondary to spinal cord injury. Urology, 2005. 65 (2): p. 306-10.

[18] Akkoc, Y., Health-related quality of life of patients using clean intermittent catheterization for neurogenic bladder secondary to spinal cord injury. Urology, 2005. 66 (6): p. 1360; author reply 1360 .

[19] Amarenco, G., et al., Pencil and paper test: a new tool to predict the ability of neurological patients to practice clean intermittent self-catheterization. J Urol, 2011. 185 (2): p. 578-82.

[20] Bakke, A., et al., Clean intermittent catheterisation-performing abilities, aversive experiences and distress. Paraplegia, 1993. 31 (5): p. 288-97.

[21] van Achterberg, T., et al., Adherence to clean intermittent self-catheterization procedures: determinants explored. J Clin Nurs, 2008. 17 (3): p. 394-402. 